\title{
Characterising Land Cover Change in Brunei Darussalam's Capital District
}

\author{
Matthew Ng
}

\author{
Zahratu Shabrina
}

July 22, 2020

\author{
Boyana Buyuklieva
}

\begin{abstract}
In fast-developing regions, like Southeast-Asia, monitoring urban areas presents a challenge given the lack of publicly available data. This is an issue that precludes the nuances of a city's growth and undermines the way land-use is considered with respect to planning. The issue of data availability is very much present in the small nation of Brunei. Little is still known about the spatiotemporal evolution of its urban realm; in particular, with regard to its national development planning. The country presents an interesting case-study given the pursuit of two highly opposing master-plans within the last 40 years. Its first master-plan advocated polycentric growth away from the capital city, Bandar Seri Begawan. Its latest plan, however, currently promotes compact growth within a predefined urban footprint as a development control mechanism. This paper looks at remotely-sensed satellite-data to examine the way in which the two implemented master-plan strategies have translated into actual land-use thus far. It employs a supervised classification procedure; and characterises urban land into three typologies: urban infill, edge growth, and leapfrog growth. The paper's findings suggest that residential developments play a stronger role in driving urban growth in Brunei. This is particularly true for public housing, which has typically persisted in isolated pockets of low-density at the city-fringe. This study has produced a novel dataset of urban land-use and land-cover in Brunei; and, its quantification may prove useful in understanding the impacts of master-planning and the formulation of development policies both within Brunei, and the wider Southeast-Asian region.

Keywords:Remote-sensing; Land-use and Land-Cover; Change Detection; Brunei; Urban Growth
\end{abstract}

\section{Introduction}

The process of urban growth is well-understood to be strongly affected by a myriad of socioeconomic, political, and environmental variables. This understanding has fundamentally been informed by observations in population studies (Chandler, 1987, Black and Henderson, 1999), infrastructure development (Duranton and Guerra, 2016, Glaeser and Kahn 2004 Bettencourt and West, 2010), economic development (Florida, 2002, Henderson, 2003; Moretti, 2004; Sinclair, 2017), and, amongst others, policy enactment (Black and Henderson, 1999: Bengston et al. | 2004). In the past three decades, these theoretical foundations have been thoroughly explored with an added element of spatial proofing that has come concurrently to advancements in computational strength and analytical software, as well as greater access to larger, more novel data-types.

However, this also leaves the quality and accuracy of research highly dependent on the consistency and availability of collected and published data. It is a consideration that has direct implications on the level and detail in which spatial analyses can be conducted. It is also one that limits locations of investigations to those where urban data is relatively more accessible and comprehensively collected. This data challenge is a global one. In rapidly developing regions, like Southeast Asia, where land-consumption has outpaced population increase, there is an urgency for in-depth monitoring to fully understand the impacts of the growth process (Seto et al., 2010). Within the region, Jones (1997) has already highlighted the gross understatement of urbanisation levels, evident in both reported national population statistics and the extent of their built environments. Sheng and Thuzar (2012) have reiterated these concerns as highly pervasive between nations and argued that the broader picture of urbanisation is still relatively unknown, which have detrimental effects on land-use planning and development monitoring.

As such, there are often inconsistencies as to what constitutes urban land-use and how urban land is consequently planned for in the region (Lim, 2004, Rimmer and Dick, 2009, Sheng and Thuzar, 2012). It further obscures the nuances of the region's growth and form, with respect to the overall landscape. This paper intends to bridge these gaps in understanding of the region's urbanisation through the use of remotely-sensed satellite imagery. In particular, it contributes Brunei as a case study to highlight the possible effects of development policy on urban growth in the country, which may prove useful in the subsequent formulation of development policy both in the country and the wider Southeast-Asian region. 
Providing a comprehensive outlook on urbanisation is undoubtedly important if results from urban data analysis are to be used in the formulation, monitoring, or modification of urban development policy. Remote-sensing, in particular, has been used in numerous studies analysing areas of limited data access to limitations in governmental datasets, their boundaries, administrative demarcations (Montgomery, 2008, Seto et al., 2010). For example, Sharifi et al. (2014) were able to assess the implementation of national development strategies on regulating urban growth and form through evaluations of land-use zoning with the use of satellite imagery in Laos. In the same vein, Nong et al. (2018) quantified the spatiotemporal changes of Hanoi's built form using remotely-sensed data to denote growth typologies for close to two decades. Other similar regional works can be found for Bangkok (Thomson and Hardin, 2000; Madhavan et al., 2001), Jakarta (Zain et al., 2015), Manila (Estoque and Murayama, 2015; Boori et al., 2016), amongst others.

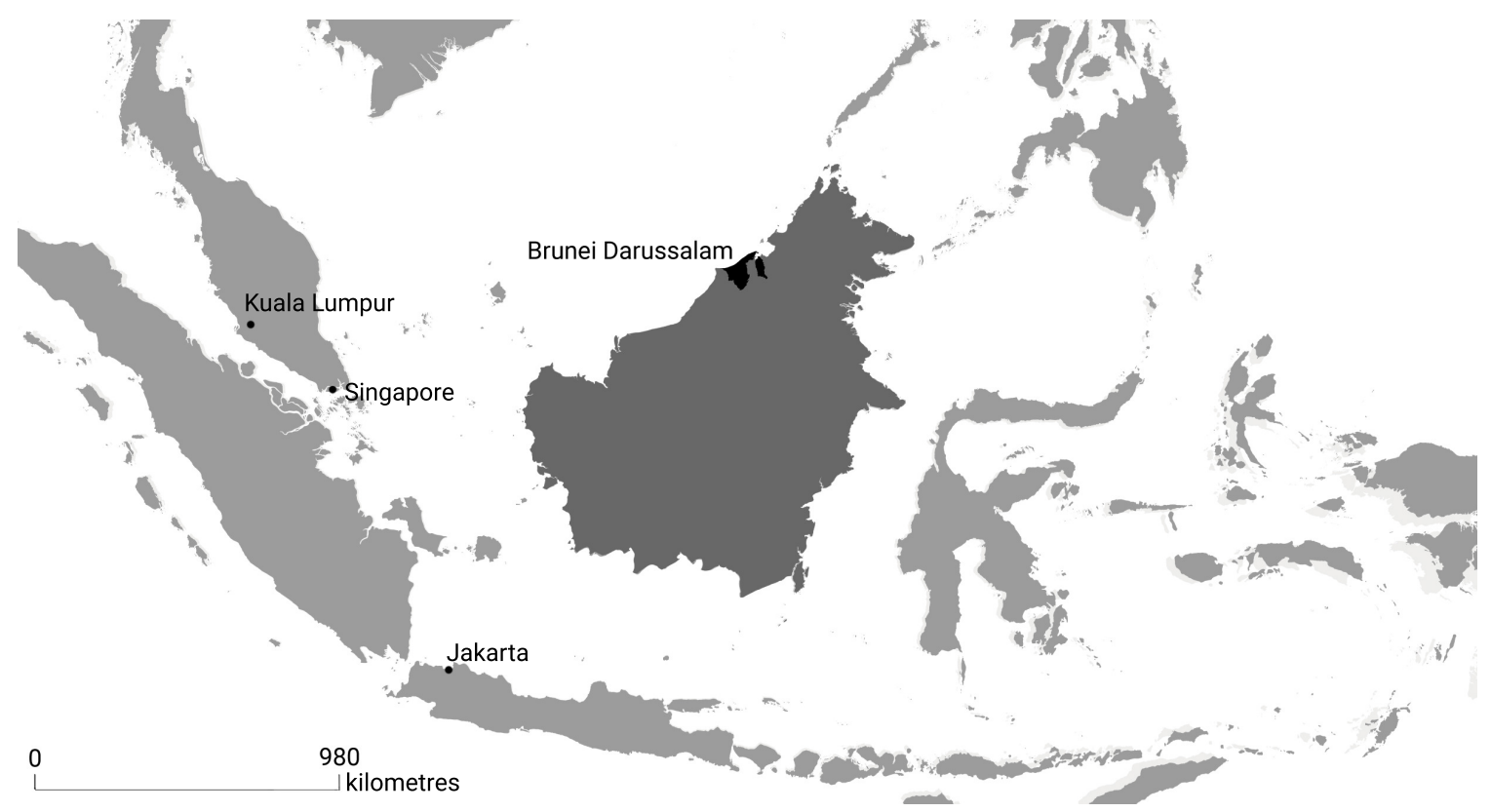

Figure 1: Brunei Darussalam within the wider Southeast Asian region. Image adapted from World Resource Institute (2011) data.

In the small nation of Brunei Darussalam (ref. Figure 1), similar data limitations to those seen throughout Southeast-Asia are also evident. Land-use, land-cover, socioeconomic, and demographic statistics that feature extensively within its plans are often the public (DTCP, 2008, 2015). Moreover, land-use components required to conduct accurate analyses of its urbanisation process fall under the jurisdictions of various ministerial departments. This is believed to constrain research into Brunei; with studies into its socioeconomic and environmental situations, as expected, the critical linkages to Brunei's overall urban development (Bakar, 2008, Becek, 2010, Hashim, 2010, Roberts, 2011; Hamdi et al., 2017). There have, moreover, been very few attempts made to analyse the spatial extent of Brunei's urban growth trajectory - with Aban et al. (2011)'s work, utilising the United States Geological Survey's (USGS) Landsat 5 Thematic Mapper (TM) and Landsat 7 Enhanced Thematic Mapper (ETM) datasets to monitor changes in land-surface temperature between 1999 to 2007, being the only study of note. 


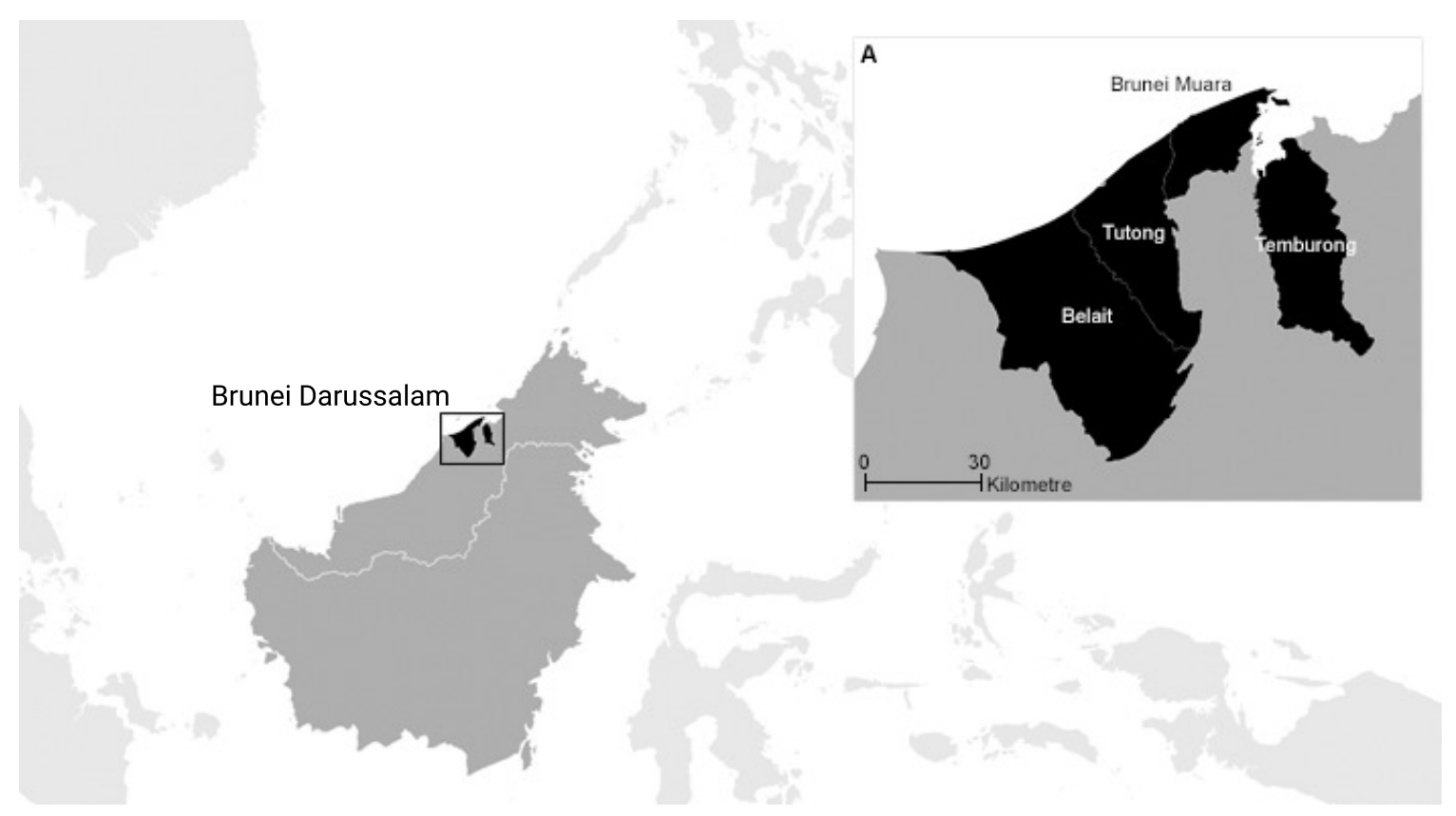

Figure 2: Brunei Darussalam is located on the northern coast of Borneo Island. It is comprised of four constituent districts: Brunei-Muara, Belait, Tutong, and Temburong. The Brunei-Muara (BM) district holds the majority of the nation's population, and administrative and economic centres. Image adapted from World Resource Institute (2011) data.

Brunei, therefore, presents a strong case for investigation in this regard. Like its Southeast Asian contemporaries, the nation has experienced a period of rapid urban growth since its independence from colonial rule in 1984. This development has been concentrated its four districts, the Brunei-Muara (BM) district (ref. Figure 2 Inset A). As the capital district, BM majority of Brunei's national ministries, the concentration of its financial and business headquarters, and the overwhelming majority of its approximate 400 thousand population (DTCP, 2015, JPKE, 2011). The district can be considered diagnostic of the way current policy may influence the country's urban development and future trajectories. However, little is still understood about this aspect of the country, to-date.

\subsection{Background}

\subsubsection{Development Planning in Brunei Darussalam}

Urban development in Brunei has proceeded under two highly opposing urban planning strategies enacted under the purview of its development master-plans in the past four decades. In the first master-plan, the Negara Brunei Darussalam Master Plan (NBDMP), a mandate for decentralisation away from Brunei's capital, Bandar Seri Begawan (BSB), was pursued through polycentric development of the district's periphery. The broader objective of this strategy was to decentralise BSB through the development of commercial and industrial centres that would be supported by the country's concurrent public housing programmes. The NBDMP was in place the period between 1986 and 2005. However, it faced numerous challenges with integration into Brunei's overarching planning and land administration systems at the time.

The NBDMP then consolidated a series of localised planning initiatives focused on specific land-use zoning throughout the BM district. However, these land-use strategies were largely unenforceable, as the NBDMP lacked clout as a statutory or regulatory document (DTCP, 2008, Hamzah and Urayama, 2018). Furthermore, with the prioritisation of land-title condition: 1 , attempts to alter land parcels in response to necessary changes in development land-use were often met with failure due to the bureaucratic inability to exert stronger planning control. This weakened administrative stance is argued to have contributed to the proclivity for low-density estates (Jones, 2010, Aban et al., 2011, DTCP, 2008); the unplanned and unrestricted changes in land-use within residential plots (DTCP, 2008$)$; and, the incongruous developments pursued under archaic land-title conditions, rather than by their assigned zoning or density (DTCP, 2008, Hamzah, 2017).

\footnotetext{
${ }^{1}$ Land-title conditions act as the Brunei's primary form of development control. These conditions were largely carried over unrevised during the period of Brunei's British occupation, and predominantly stipulate agricultural requirements within each land parcel (Horton. 1986, Jones. 2010).
} 
Revisions were deemed necessary by the Bruneian Government in the face of the nation's increasingly sprawling character to regulate land-consumption in the nation through increased densification (DTCP, 2008, 2015, Hamzah, 2017). As such, the second iteration of Brunei's national master plan, the National Land Use Master Plan (NLUMP), urbanisation through policy footprint of the BM district (DTCP, 2008, 2015). The NLUMP was promulgated in 2006 for the current period up to 2025. However, it has been argued that the reinforcement of NLUMP actual urban development still considerably hampered (Hamzah, 2017, Hamzah and Urayama, 2018). Like the NBDMP, the NLUMP not exist statutory document within the Bruneian land-administration system. This leaves the current situation of Brunei unchanged; and, more importantly, vulnerable the repetition of past planning impairments, like those seen during the NBDMP's period.

It is also interesting to note that the NLUMP's densification strategies do not necessarily pertain to other government-led development projects, large-scale public housing programmes. Brunei's two primary housing initiatives, the Skim Tanah Kurnia Rakyat Jati (STKRJ) and the Rancangan Perumahan Negara (RPN), are both arguably the country's most significant development undertakings (Yunos, 2008, Oxford Business Group, 2011); and, both have been instrumental in driving much of the early NBDMP policies for decentralised growth away from BSB through public housing development in the BM district's periphery ${ }^{2}$ The main housing typology adopted within these programmes were traditionally detached, single-family dwellings (McGarrigle, 1994, Yunos, 2008: Oxford Business Group, 2016); with, more recent years seeing increased densities through the development of terrace housing (Oxford Business Group, 2016). They nevertheless typically remain highly circumscribed within large, homogeneous residential estates, which McGarrigle (1994) has previously argued to be reminiscent of Howard (1965)'s Garden City model.

The increasingly low-density form of urban land-use in Brunei has since become emblematic of its urban character. Indeed, with the heavy influence that land-use and consumption, it is necessary to question how the policy may act in fulfilment of the nation's development ambitions. What is nevertheless clearly apparent within the shifts policies and attitudes between Brunei's two master-plans however are the tensions that exist between a desire for individual, space-intensive dwelling and the depleting amount of land available for development in Brunei. Despite these tensions, the impacts of the country's development planning strategies have yet to be quantified. Consequently, unclear if more novel policy mechanisms, like the NLUMP's urban footprint as development containment tool, has been able to facilitate any marked changes in land-use in Brunei thus far.

This paper thus land-use and land-cover changes as a starting point to understanding the effects of policy on the built environment. Land-consumption in the BM district will be investigated through the use of remotely-sensed various USGS Landsat sensors between 1981 and 2011, in decadal intervals. Adapting work by Liu et al. (2010) and Nong et al. (2018), the BM district's urban growth is characterised and further evaluated against key urbanisation objectives set within its national development plans. Attention is also paid to Brunei's public housing schemes as a driver for new growth within the district; and, the study identifies and discusses the possible effects these national planning policies may have on Brunei's citizens.

The following sections will present the methodological approaches taken in this study, with the results discussed throughout. Lastly, it will discuss its findings on Brunei's built-up character with regards to Brunei's previous and current development planning strategies and conclude with recommendations for policy and further study.

\section{Data and Methodology}

\subsection{Study Area}

The BM district is the smallest of Brunei's four constituent districts in terms of land-mass. However, despite its size, the district is home to a majority of the country's population and national urban development projects (Oxford Business Group 2016 JPKE, 2017). BM is comprised of 12 in-land, and a further six individual sub-districts constituting its historic water village, Kampong Ayer (KA) (ref. Figure 3). Within these 12 in-land sub-districts, there is a total of 177 villages. KA is comprised of 6 constituent sub-districts, with 39 individual village-level denominations; however, this paper will henceforth refer to these singularly as KA. This aggregation of KA insofar does not have impacts with respect to planning policy formulation, and the nomenclature is widely adopted Brunei's planning policies.

The geographical location of KA is of historical importance to Brunei's development timeline. It features as Brunei's first major urban core having persisted throughout much of the country's occupation under British colonial rule (Hamdi et al. 2017). In fact, up to the early seventies, KA held over 60 per cent of the country's entire population (Mansurnoor, 1997). Subsequent peripheral expansion in-land from KA towards Kianggeh is thought to have fully established BSB as the capital

\footnotetext{
${ }^{2}$ Early housing provisions under the RPN allocated eligible residents with land up to two acres (Yunos 2008).
} 


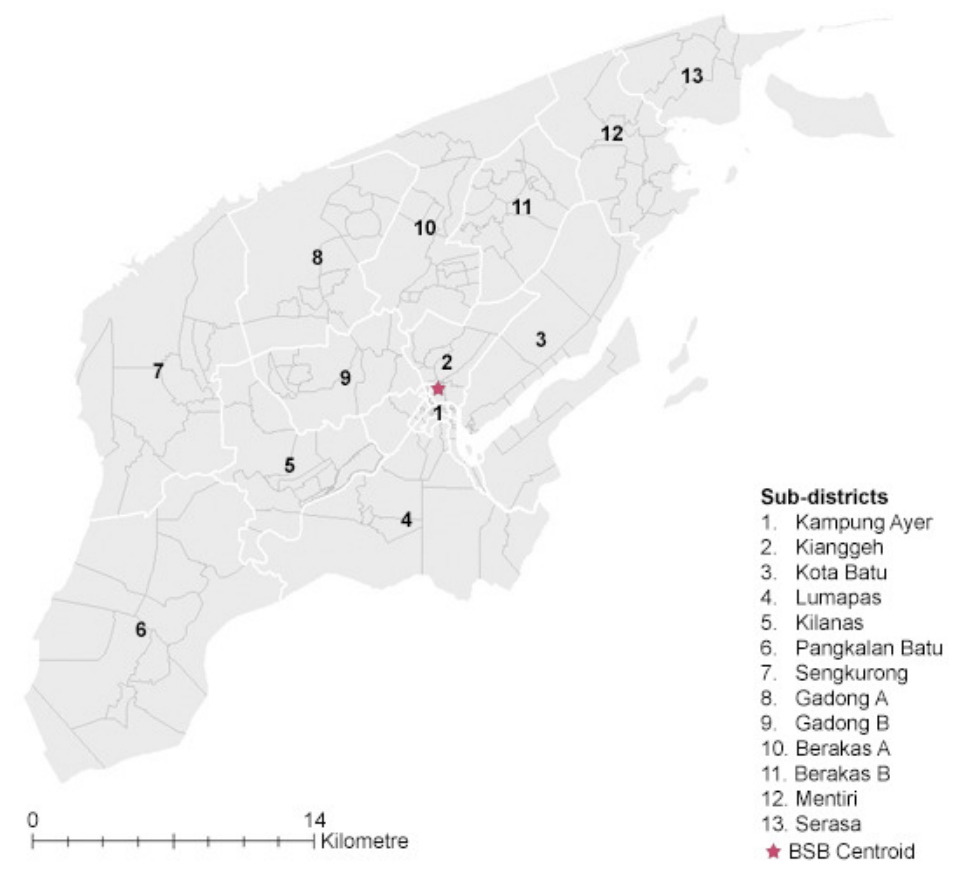

Figure 3: Sub-district of Brunei Muara. Image adapted from data obtained the Ministry of Development (2017).

of contemporary Brunei (McGarrigle, 1994). Considering this, this study has assigned the centre of the BM district to Pusat Bandar, adjacent to KA, in the Kianggeh sub-district for its analysis of Brunei's urban evolution (ref. Figure 3 ).

\subsection{Data}

\subsubsection{Administrative and Residential Boundaries}

Administrative boundaries were obtained from the Survey Department of Brunei's Ministry of Development. This dataset, which is updated and accurate up to 2017, comprises Brunei's road network and residential cadastral parcels, in addition to demarcations for the district-, sub-district-, and village-levels. The dataset has been processed and integrated across each layer to correct for any incidence line errors. It follows the Geocentric Datum for Brunei Darussalam (GDBD 2009) coordinate reference system. Its compatibility with World Geodetic System (WGS) 1984 datum should be noted with respect to the raster data used in this study.

\subsubsection{Remotely-sensed Data}

The study's dataset was obtained from the USGS Landsat Programme. Image scenes were downloaded from the EarthExplorer Platform ${ }^{3}$ with the main selection parameters as a maximum of 10 per cent cloud cover and three-year threshold from each study period. The respective dates and source sensors for each study year are listed in Table 1. The choice of multiple Landsat sensors was due to their different operational periods: Landsat 5 TM (1984-2013), Landsat 7 ETM + (1999-present), and Landsat 8 Operational Land Imager (OLI) and Thermal Infrared Sensor (TIRS) (2013-present). All scenes downloaded from the Landsat programme are from the Level-2 collection, which have already undergone pre-processing and calibration steps to obtain image surface reflectance values (USGS, 2019).

\footnotetext{
${ }^{3}$ Website available at: https://earthexplorer.usgs.gov/
} 


\begin{tabular}{lccc} 
Study Year & Satellite & Date & Number of Bands \\
\hline 1981 & Landsat 5 TM & $26 / 05 / 1982$ & 7 \\
\hline \multirow{2}{*}{1991} & Landsat 5 TM & $\begin{array}{l}23 / 07 / 1988 \\
08 / 03 / 1992\end{array}$ & 7 \\
\hline \multirow{2}{*}{2001} & Landsat 7 ETM+ & $\begin{array}{l}07 / 10 / 2001 \\
13 / 12 / 2002\end{array}$ & 8 \\
\hline \multirow{2}{*}{2011} & Landsat 8 OLI/TIRS & $\begin{array}{l}09 / 01 / 2013 \\
07 / 03 / 2013\end{array}$ & \multirow{2}{*}{11} \\
\hline
\end{tabular}

Table 1: Study-year multispectral image and their corresponding sensor source, recorded date, and number of bands. It should be noted that the Cirrus band, Long-wave Infrared bands, and Panchromatic bands were omitted from downstream pre-processing step to minimise resampling errors.

\subsection{Methodology}

\subsubsection{Raster Processing and Image Enhancements}

Image processing of the obtained Landsat data was conducted with specific steps taken depending on the needs of each individual dataset. Raster composites for study years 1991, 2001, and 2011 were created from their numerous constituent scenes. Each image was then manually altered with a per cent clip stretch to control the brightness and contrast of the raster.

\subsubsection{Normalised Differences and Thresholds}

Four Normalised Difference (ND) indices were created for built-up, water, vegetation, and bare-soil cover at each study year. The objective of this was to create specific probabilistic land-cover masks that can be used in downstream classification training to minimise user-bias and overcome the lack of ground truth data (Haug et al., 2014). For vegetation land-covers, a Normalised-Difference Vegetation Index (NDVI) was derived using Rouse Jr et al. (1973)'s formula (ref. Equation 1),

$$
N D V I=\frac{(N I R-R e d)}{(N I R+R e d)}
$$

... whereby, the Near-infrared (NIR) and the Red band layers are used. In line with this general formula, a Modified Normalised Difference Water Index (MNDWI) was also derived, following work by $\mathrm{Xu}(2006)$ with the Green Band and the Short-wave Infrared Band 1 (SWIR1). Bare soil cover was obtained using the Normalised Difference Bare-soil Index (NDBSI) formulated by Chen et al. (2004). The NDBSI utilises the SWIR1 and Rend band reflectance. And, lastly, built-up cover was derived from Bhatti and Tripathi (2014)'s more recent Normalised Difference Built Index (NDBI), with the SWIR1 Band and as the NIR Band. Raster masks were then derived by subsetting the minimum values of each index ND value to the its first quartile. These derived surface masks were used then for subsequent classifier training (ref. Figure 4 ).

\subsubsection{Image Classification}

An object-based supervised maximum-likelihood (ML) classification procedure was used for the land-use analysis. The choice of this classifier arose from comparison between a Support Vector Machine, Random Forest, in addition to pixel-based and object-based ML classifiers on the 1981 study dataset (ref. Figure 5.). Their accuracies were then tested with a sample subset of the study's five land-use types with respect to their overall accuracies and their Cohen's Kappa. Based on this comparison, it was found that the object-based ML classifier displayed to most promising results than its counterparts; and, as such, its use was opted for this study. The results of these preliminary classifications are listed in Table 2

This procedure automates the raster classification based on the variance in the spectral response of each raster image (Lillesand et al., 2014). A user-generated sample dataset for five land-use classes — Water, Bare Soil, Rainforest, Grassland, and Built-up — was created to provide the ML classifier with a baseline of land-cover response values. A minimum of 200 training samples was derived from points created using the previously created ND masks for each study year. Bare Soil surface 

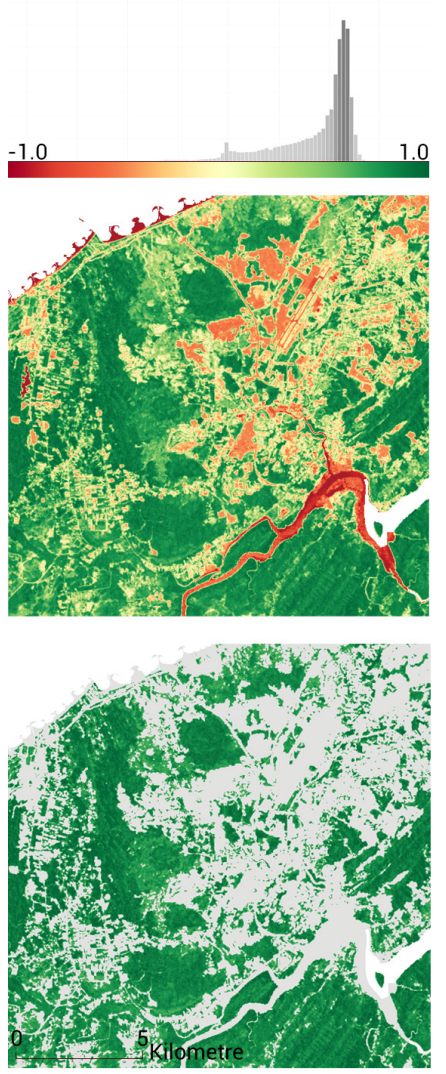

Rainforest Mask
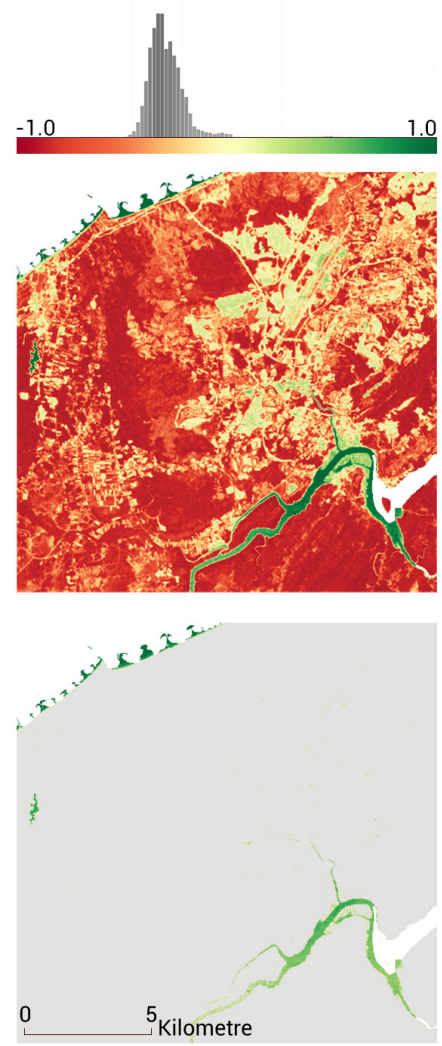

Water Mask
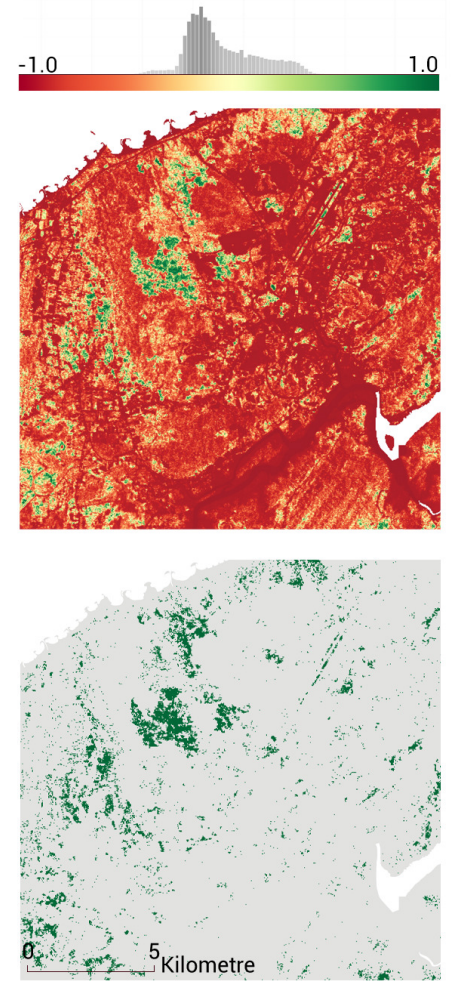

Bare Soil Mask
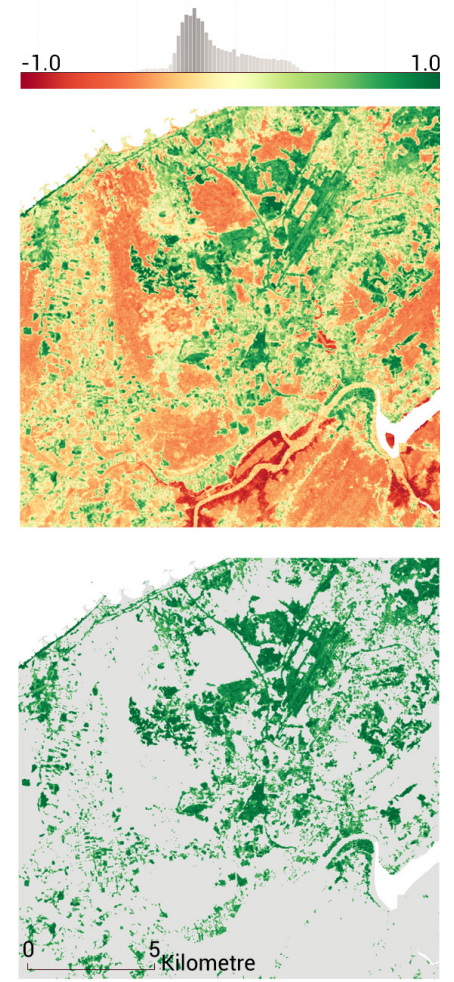

Built-Up Mask

Figure 4: Normalised Difference indices visualised for vegetation, water and built-up cover in 1991.

\begin{tabular}{lllll} 
& ML-P & ML-O & RF & SVM \\
\hline Overall Accuracy & 0.80 & 0.87 & 0.74 & 0.80 \\
Cohen's Kappa ( $\kappa)$ & 0.75 & 0.83 & 0.63 & 0.67
\end{tabular}

Table 2: Overall Accuracy and Cohen's $\kappa$ values for classifier testing. ML-P denotes the pixel-based maximum likelihood classification; ML-O denotes the object-based maximum likelihood classification; RF denotes the random forest classification; and, SVM denotes the support vector machine classification.

covers were sampled based on field knowledge and ancillary maps. These sample inputs were predominantly cleared land around development sites throughout the BM district, and major agricultural areas in Wasan and Batu Ampar village areas. Post-classification change detection was conducted using pixel-comparisons for each year. The total areas of each land-use class were derived from the relative abundance of each pixel type, accounting for the resolution of 30 by 30 metres for Landsat $5 \mathrm{TM}+$; and, 15 by 15 metres for Landsat $7 \mathrm{ETM}+$ and Landsat $8 \mathrm{OLI} / \mathrm{TIRS}$. An Average Annual Growth Rate (GR) for each land-use class was then calculated, using Equations 2 , to assess the overall change in land-use class over the study period.

$$
G R=\frac{\text { Change }_{a}+\ldots+\text { Change }_{t}}{T}
$$

where, $T$ refers to the total number of periods, and Change is calculated with Equation 3 .

$$
\text { Change }=\frac{\text { Area }_{t}-\text { Area }_{0}}{\text { Area }_{0}}
$$



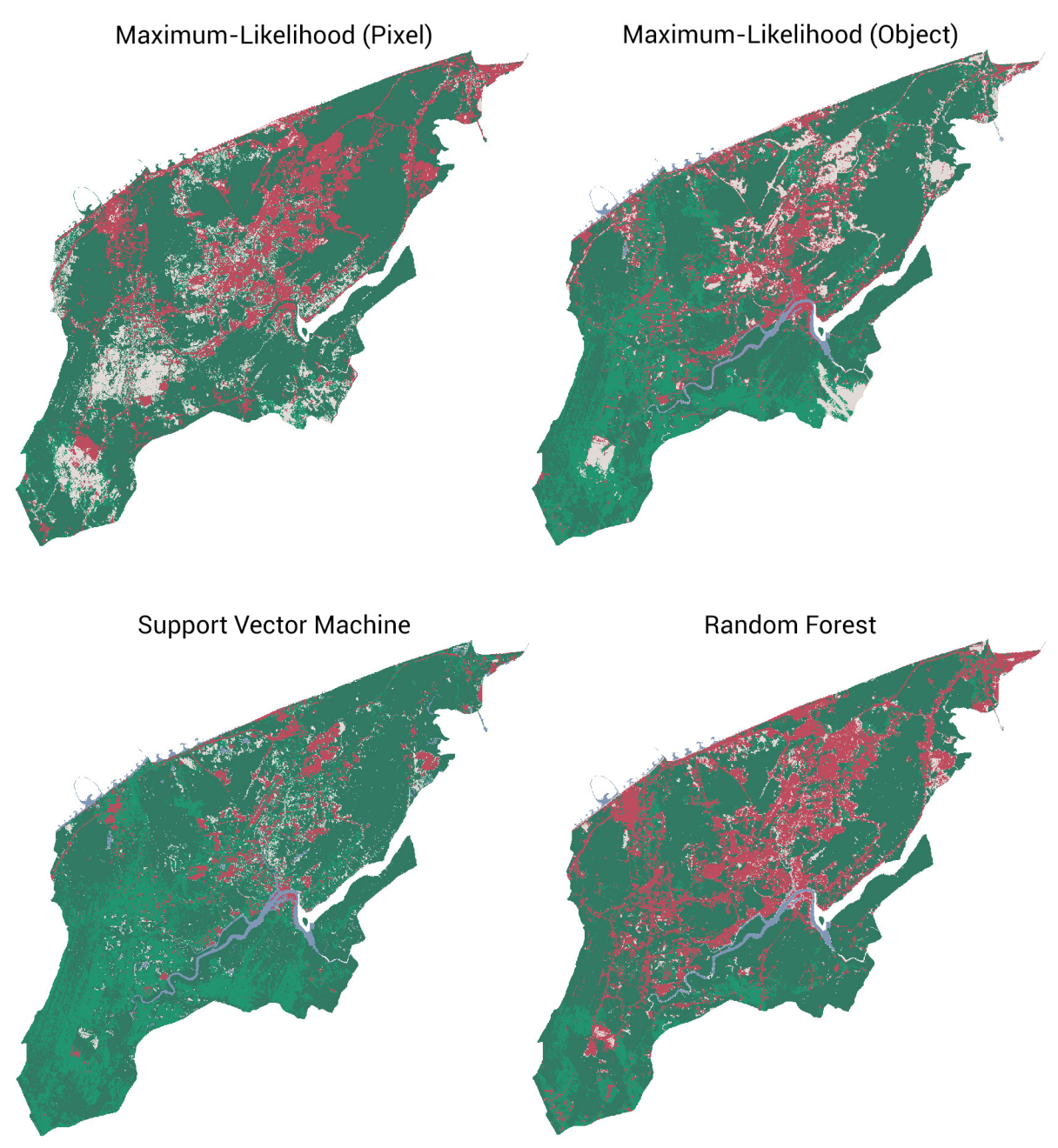

Bare Soil Built-up Grassland $\square$ Rainforest Water

Figure 5: Comparative results of four classifier types on the 1981 BM district scene.

\subsubsection{Accuracy Assessment and Change Detection}

Accuracy assessments of the classification process were conducted individually for each year for a random subset of pixels, for which ground truth data has been gathered. A stratified random sample of over 150 ground truth points per image was created for the user-classified images. These were cross-referenced with existing field data and topographical maps dated for each year of the analysis. A classification error matrix was constructed from this and scored, with a convention of 85 per cent as a minimum accuracy threshold (Anderson et al. 1976, Foody, 2002). The classifier was retrained, and the classification process was reiterated if analyses fell short of this accuracy threshold. Over the four study period, the model shows an average accuracy of 88 per cent (ref. Table 3). It should be noted that the average accuracy score may not allude to the cumulative classification error between each year. The implications of this are discussed in the proceeding results discussion.

\begin{tabular}{l|cccc} 
& $\mathbf{1 9 8 1}$ & $\mathbf{1 9 9 1}$ & $\mathbf{2 0 0 1}$ & $\mathbf{2 0 1 1}$ \\
\hline Overall Accuracy & 0.87 & 0.87 & 0.89 & 0.89 \\
Cohen's Kappa $(\kappa)$ & 0.83 & 0.79 & 0.70 & 0.82
\end{tabular}

Table 3: Classification model's Overall Accuracy and Cohen's Kappa scores.

Table 3 also provides the results of the image classification model's Kappa Index. This is used to assess the predictive performance of the land-cover classification, in comparison to the expected results of a random classifier. The study's Producer Accuracy (PA) and User Accuracy (UA) values for each land-use class and study-year, derived from their respective commission (C) errors (due to misclassifications) and omission (O) errors (due to exclusions), are provided in Table 4 These 
values are indicative of the reproducibility of each land-use class using the supervised-learning classification. Average PA and CA values for the model across all years are 0.83 and 0.85 , respectively.

\begin{tabular}{|c|c|c|c|c|c|}
\hline \multirow{7}{*}{ 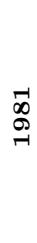 } & Class & PA & UA & C & $\mathrm{O}$ \\
\hline & Water & 1.00 & 1.00 & 0.00 & 0.00 \\
\hline & Bare Soil & 0.53 & 0.67 & 0.33 & 0.47 \\
\hline & Rainforest & 0.94 & 0.87 & 0.13 & 0.06 \\
\hline & Grassland & 0.84 & 0.90 & 0.10 & 0.16 \\
\hline & Built & 0.94 & 0.84 & 0.16 & 0.06 \\
\hline & Class & PA & UA & C & $\mathrm{O}$ \\
\hline \multirow{5}{*}{ 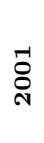 } & Water & 0.75 & 1.00 & 0.00 & 0.25 \\
\hline & Bare Soil & 0.81 & 0.65 & 0.35 & 0.19 \\
\hline & Rainforest & 0.99 & 0.94 & 0.06 & 0.01 \\
\hline & Grassland & 0.70 & 1.00 & 0.00 & 0.30 \\
\hline & Built & 0.83 & 0.89 & 0.11 & 0.18 \\
\hline
\end{tabular}

\begin{tabular}{|c|c|c|c|c|c|}
\hline \multirow{7}{*}{$\underset{\sim}{\stackrel{\sigma}{\sigma}}$} & Class & PA & UA & C & $\mathrm{O}$ \\
\hline & Water & 0.67 & 1.00 & 0.00 & 0.33 \\
\hline & Bare Soil & 0.67 & 0.53 & 0.47 & 0.33 \\
\hline & Rainforest & 0.94 & 0.93 & 0.07 & 0.06 \\
\hline & Grassland & 0.79 & 0.79 & 0.21 & 0.21 \\
\hline & Built & 0.86 & 1.00 & 0.00 & 0.14 \\
\hline & Class & PA & UA & C & $\mathrm{O}$ \\
\hline \multirow{5}{*}{ స్త } & Water & 1.00 & 0.50 & 0.50 & 0.00 \\
\hline & Bare Soil & 0.85 & 0.77 & 0.23 & 0.15 \\
\hline & Rainforest & 0.96 & 0.93 & 0.07 & 0.04 \\
\hline & Grassland & 0.63 & 0.91 & 0.09 & 0.38 \\
\hline & Built & 0.86 & 0.88 & 0.12 & 0.14 \\
\hline
\end{tabular}

Table 4: Classification accuracy tables for each study year indicating the Producer's Accuracy, User's Accuracy, Commission, and Omission scores.

\subsubsection{Satellite Imagery and GIS Data Integration}

Integration of the Census-GIS data enables finer analysis of Brunei's land-cover and land-use change by providing more detailed information on designated land-use. Residential land-use zones, in particular, can be delineated and extracted in this way through the use of the study's available cadastral boundaries. Built-up areas within post-classified images in each year were first identified and subset to ensure that only the relevant land-use class was included in later processing. The extracted built-up class dataset was then intersected with the provided residential boundaries to obtain only residential neighbourhoods within each scene. This process was repeated for each study year to enable pixel change comparisons for each study year.

\subsubsection{Land-cover Characterisation}

Patterns of land-use were characterised using two indices: the Landscape Expansion Index (LEI) and Area-Weighted Mean Expansion Index (AWMEI). These were calculated for all post-classified, satellite imagery built-up areas, but also the extracted residential areas.

Firstly, the Landscape Expansion Index (LEI) individual growth areas were determined with Equation 4 . In this equation, $L_{c}$ refers to the length of the shared perimeter of a newly grown area to the existing built fabric; whilst, $P$ refers to the total perimeter of the newly grown area. These perimeter values are derived from the post-classified images by looking at the difference between subsequent study years and applying a line intersection analysis to obtain shared boundary values. Based on Liu et al. (2010)'s and Nong et al. (2018)'s work, the LEI values of each growth area can be characterised as edge-growth $(0<L E I \leq 0.5)$, infill $(L E I>0.5)$, and new growth or leapfrog development $(L E I=0)$.

$$
L E I=\frac{L_{c}}{P}
$$

An Area-Weighted Mean Expansion Index (AWMEI) was then calculated with Equation 5 where $L E I_{i}$ is the LEI value for each classified growth patch $i ; a_{i}$ considers the area in $m^{2}$ of these expansion patches $i$; and, $A$ considers the total area of all other expansions of $i$. As previously described by Nong et al. (2018), relatively higher values of AWMEI are indicative of more compact growth; with higher values obtained between study years suggesting a phase of urban coalescence and densification.

$$
A W M E I=\sum_{i=1}^{N} L E I_{i} \cdot\left(\frac{a_{i}}{A}\right)
$$

In the next step, twelve buffers zones, at 2-kilometre increments, were created to identify differences between the spatial distribution of the LEI and AWMEI values for each study year (ref. Figure 6). The buffer zones are concentric around Pusat Bandar because, as previously discussed, it is the centre of Brunei's historic core. These buffers were then subset into four zones for the interpretations of LEI and AWMEI values. These zones correspond to a Northeast-, Northwest-, Southeast-, or Southwest- movement away from the BSB centroid. 


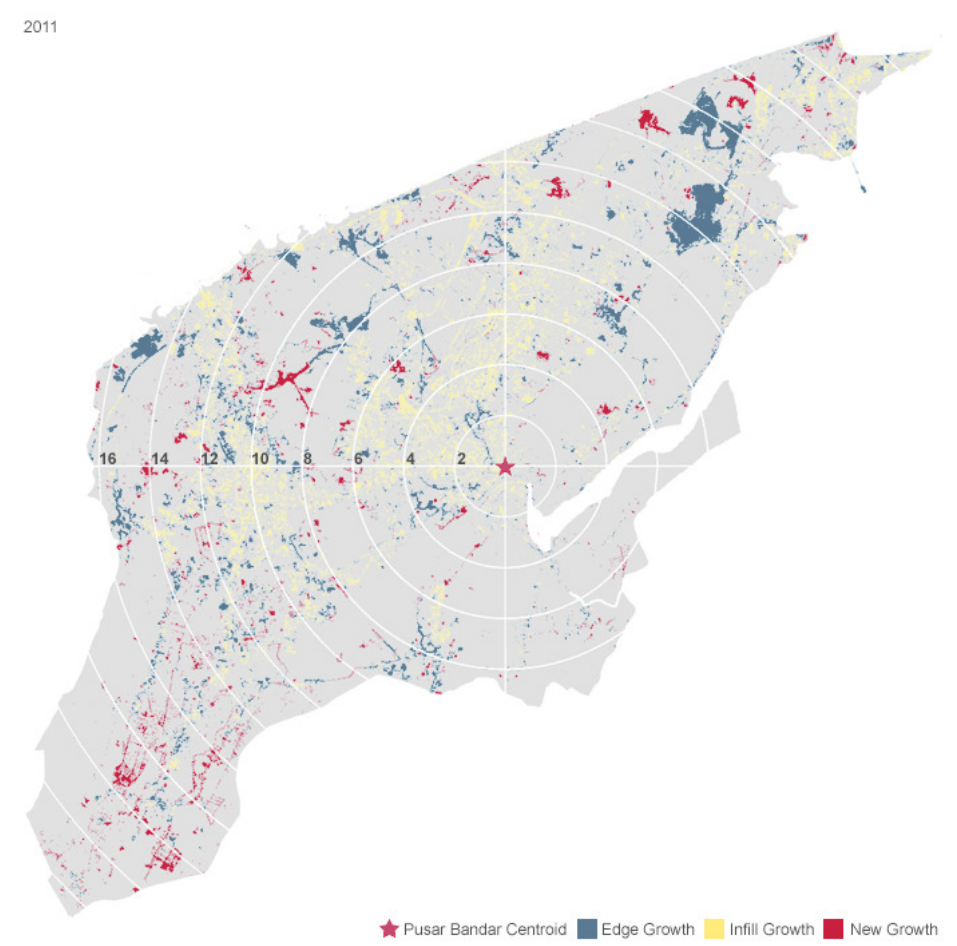

Figure 6: Area buffers at 2-kilometre increments from Bandar Seri Begawan shown against residential development typologies in 2011. Direction is derived from quadrant division of each buffer.

\section{Results}

\subsection{Land-cover Change}

The overall results of obtained from the study's image classification of the BM district are indicated in Figure 7 . And, the spatial distribution of the land-cover classes is illustrated in Figure 8. It is apparent that, with the exception of the Water and Built-up classes, individual land-cover types in Brunei have generally shown a decrease in total areas.

The classification of Water in the BM district has shown marginal growth over the past 40 years, with increases in the number of water-bodies seen in the Kota Batu, Mentiri, and Pangkalan Batu sub-districts. This increase corresponds to the development of the Imang Reservoir and the Mengkubau Reservoir between the 2001 and 2011 study periods. It should be mentioned that the inflated GR value of 22.7 in Gadong A sub-district, which has been attributed to a commission error in 2011 of a Bare Soil surface cover. No significant change for this class is seen across all other sub-districts.

In the Bare Soil class, there has been an overall decrease of approximately 11 per cent over the study period. The highest recorded areas can be seen between the years 1991 and 2001. These years indicate large swathes of cover in the Berakas and Gadong sub-districts; which, have been shown to correspond to the large-scale developments of the Berakas Housing Estates 4 and the Rimba Housing Estates. Similar conversions from Bare Soil classifications to Built-up are also noted in the Mata-Mata village area in 1991 and the Katok Housing Estates. The period which these developments have occurred link directly to the height of Brunei's housing development. It is interesting to note that Bare Soil classes in the study period also show plasticity in converting to Built-up and Vegetation classes. Fluctuations in the total area of Bare Soil classifications in the Pangkalan Batu sub-district soil and greenery alternations predominantly in the agricultural lands in Batu Ampar, Wasan, Panchor Murai, and Parit. And, as such, it is difficult to deduce whether Bare Soil land-covers can be considered a precursor to Built-up classes despite being a development induced state (i.e., subsequent neglect of Bare Soil classes have been shown to result in secondary vegetation types that alter resulting land-cover results). Built-up classes within the present scope of this study. A change probability could, however, be calculated in models of Brunei's possible growth scenarios.

The vegetation classes in the study include both Rainforest and Grassland areas. Grassland, here, refers to secondary vegetation classes that are. A vegetation-cover area of $412.9 \mathrm{~km}^{2}$ was indicated in 1981 , which corresponds to approximately

\footnotetext{
${ }^{4}$ The Berakas Housing Estates comprised of several smaller estates in Lambak Kanan, Lambak Kiri, and Anggerek Desa village areas.

${ }^{5}$ The Rimba Housing Estates is comprised the Rimba RPN Areas 1-5.
} 

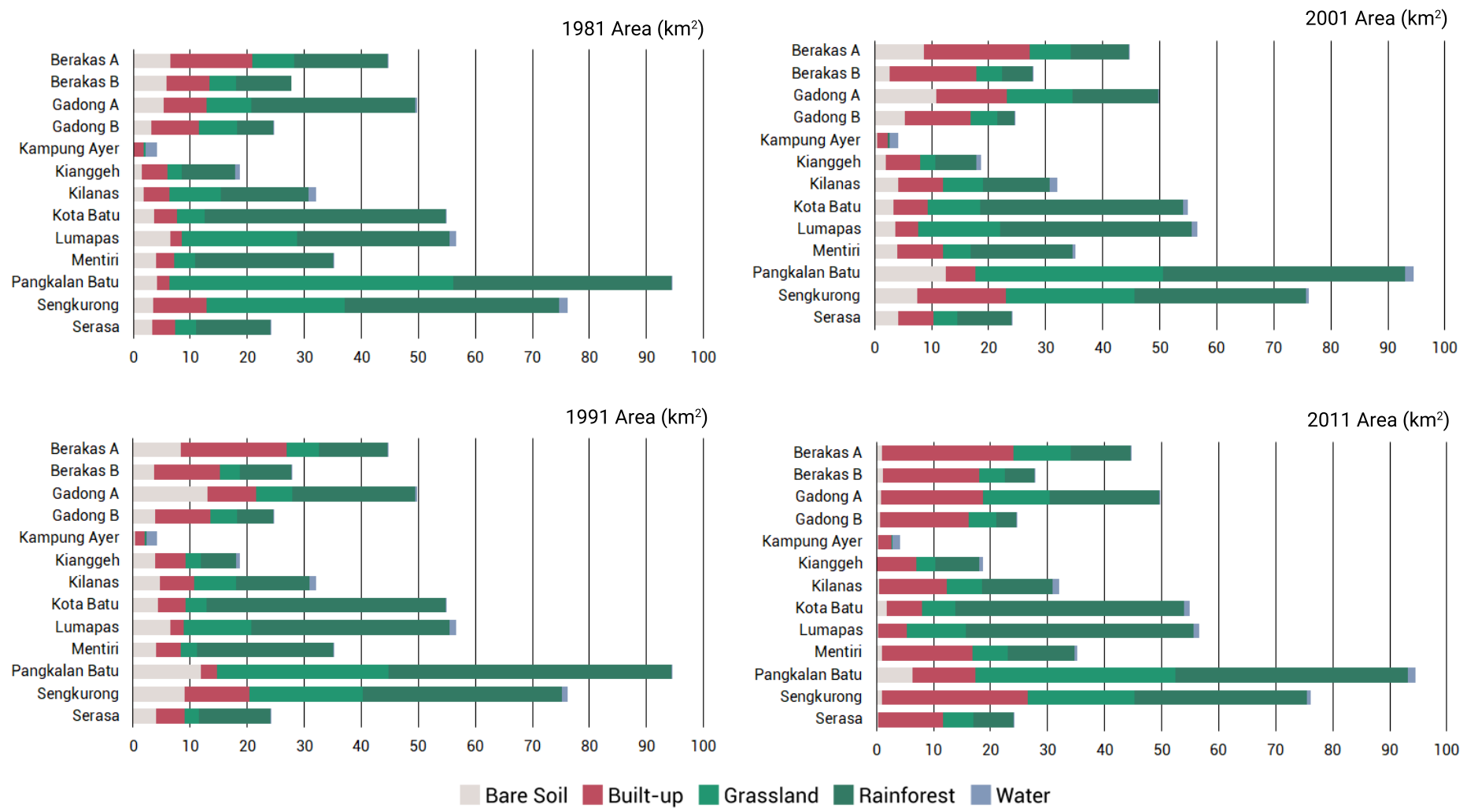

Figure 7: Land-cover classification of the Brunei-Muara district from 1981 to 2011.

76 per cent of the BM district's total land-mass. Over the 1981-2011 study period, the loss of vegetation land-cover totalled approximately $62.4 \mathrm{~km}^{2}$, comprising 64.5 per cent of the BM district. More specifically, rainforest areas have indicated a GR of approximately 5 per cent, with the greatest loss of the Rainforest cover seen in the Gadong, Berakas, Mentiri and Sengkurong sub-districts. In 2011, the largest proportional loss of Rainforest is recorded in the Mentiri sub-district, which is attributed to the more recent development of the Mengkubau RPN Areas and the Mentiri RPN Areas. The change in Grassland cover has also shown a decrease in area throughout the study period, with relatively higher losses of cover seen between 1981 and 1991. Fluctuations in the total area of Grassland cover is recorded particularly in the Lumapas and Pangkalan Batu sub-districts. This may be related with the Bare Soil cover types in the area, indicating a level of seasonality given the area's arable land-use.

The Built-up class has shown the greatest gains total area compared to all other land-use classes in the BM district over the entire study period. In 1981, total Built-up class areas were recorded at close to $73.4 \mathrm{~km}^{2}$, increasing by a factor of around 2.33 in 2011. The total Built-up area recorded in 2011 indicates that the class comprised over 31 per cent of the total land-area - a significant increase from the 13.5 per cent recorded in 1981. Built-up classes in 1981 mainly concentrated around the Pusat Bandar area, with ribbon development evident along Subok, Kota Batu, and Jalan Tutong towards the secondary Muara port-town. However, in subsequent years, there have been marked increases across all sub-districts, with exceptions to the largely agricultural sub-districts of Lumapas and Pangkalan Batu. 

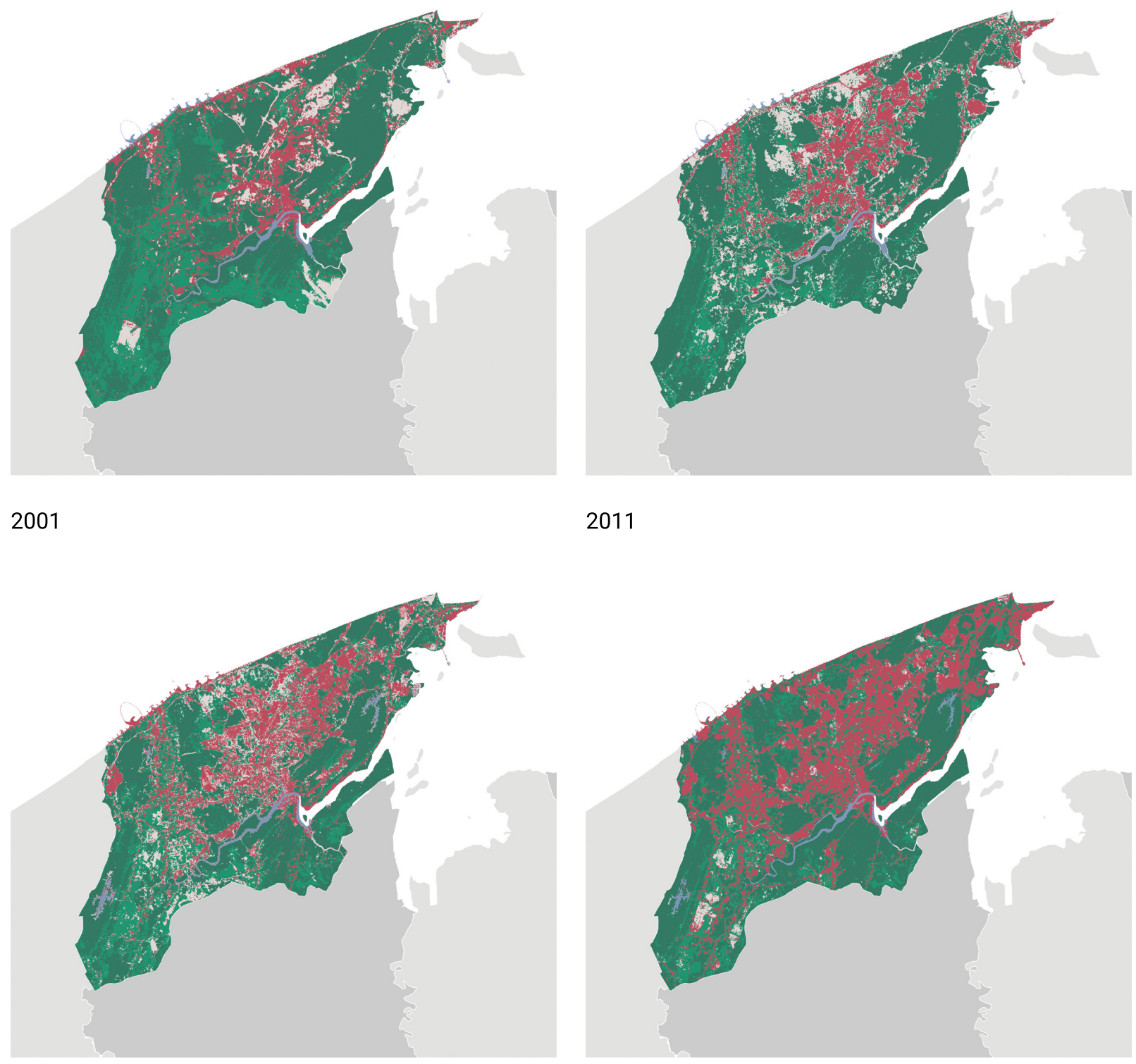

Bare Soil Built-up Grassland Rainforest Water

Figure 8: Land-use and Land-cover areas in the BM district between 1981 and 2011. 


\subsection{District Urban Development Trends}

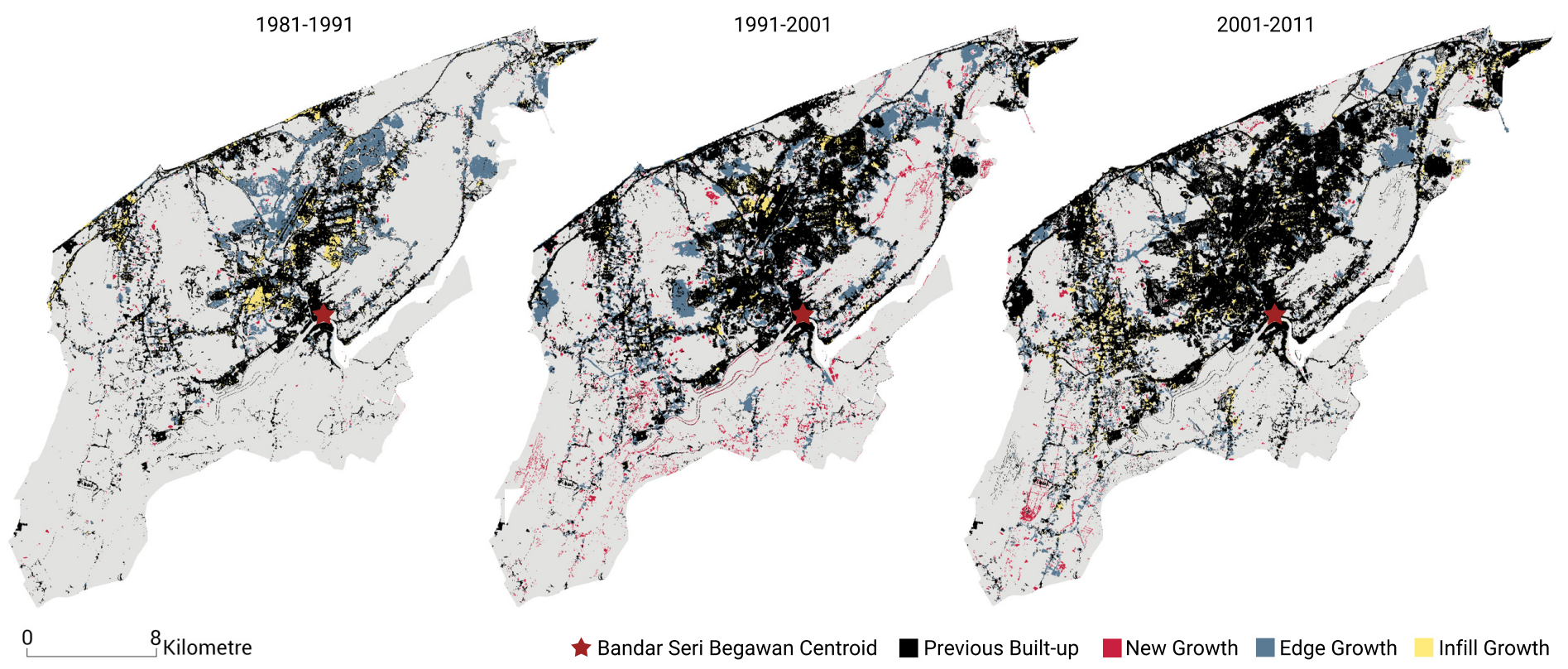

Figure 9: Development characterisation of built-up class according to new growth, infill growth, and edge growth typologies.

Further analysis of the built-up land-cover has characterised growth into three additional typologies: edge growth, infill growth, and new growth or leapfrog development. The spatial distribution of these various growth typologies is illustrated in Figure 9. The relative proportion of each built-up typology and their relative compactness scores, indicated by the AWMEI values, are indicated in Figure 10 against increasing distance from Pusat Bandar.
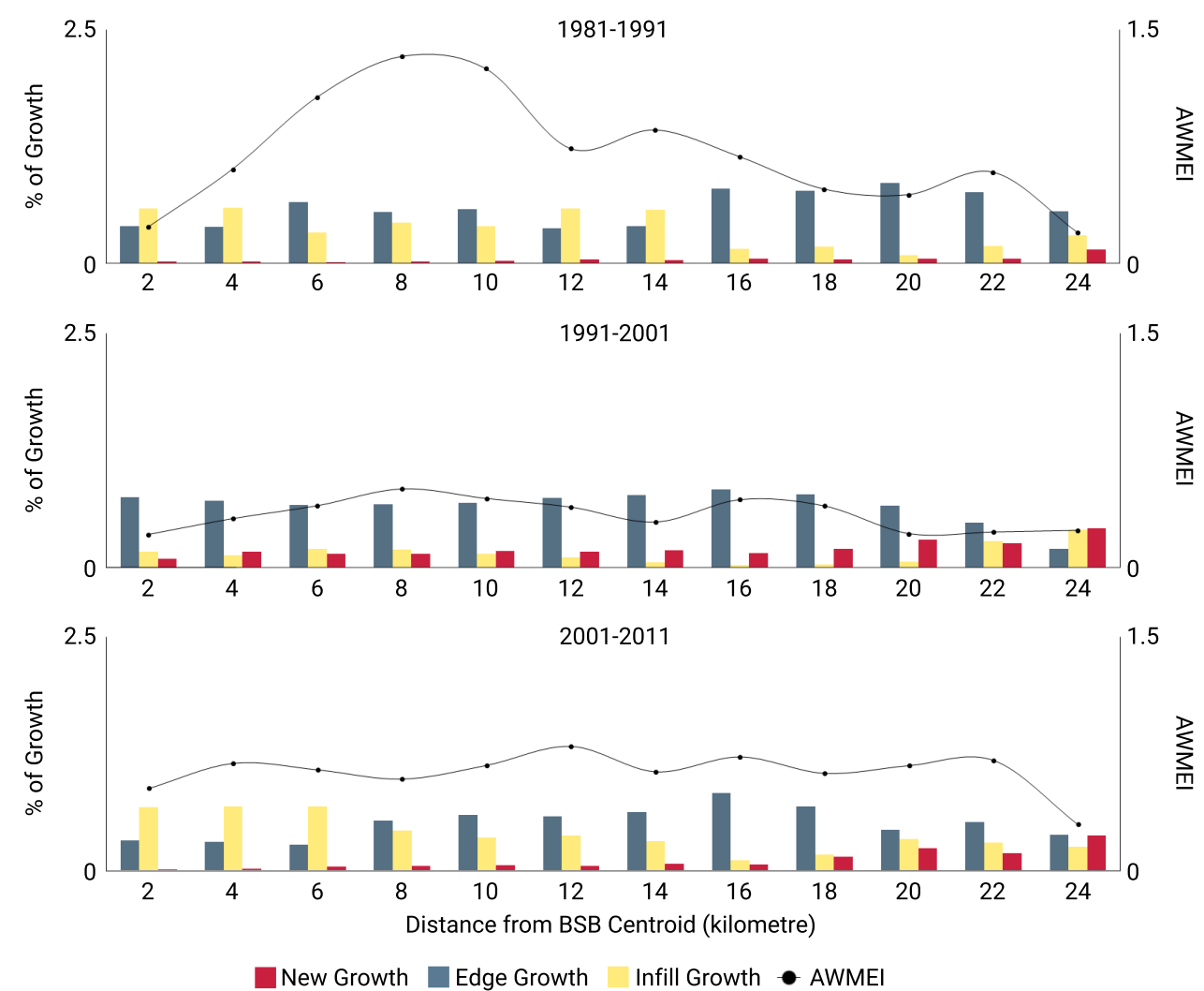

Figure 10: Area-weighted Mean Expansion Index and proportional area of development typologies across increasing distances from Bandar Seri Begawan. 
The results of this analysis indicate a marked difference between the relative compactness of new development in the BM district across the three study periods. Between 1981 and 1991, the average AWMEI is recorded at 0.71, decreasing period to an average AWMEI of 0.34. High-levels of more compact growth seen up to 10 kilometres from Pusat Bandar, whereas infill growth within this distance boundary is predominantly seen towards the centre of the BM district, extending in a North-east direction from Gadong to Berakas. Edge growth is indicated as the primary growth typology extending from the 16 to 22 kilometre distance threshold from the main urban centre of BSB. The results of the study suggest a phase of relatively high urban densification progressing concentrically within the BM district during this time, with lower levels of peripheral new growth occurring.

However, in the following period between 1991 and 2001, this almost monocentric growth does not appear present. New development during this period can be considered more diffuse, as indicated by the lower AWMEI values throughout the entire district. Relatively higher proportions of new growth and leapfrog developments are seen throughout all distances boundaries from BSB. The proportion of new growth throughout the entire district is recorded at 19.6 per cent, an increase from the previous periods 2.6 per cent. This has been shown to be likely caused by the discontiguous development of private housing from other Built-up areas. A clear example of this can be seen in the Sengkurong sub-district, which is comprised of a large number of new development clusters that are proximate, but not adjacent, to other built-up land-covers.

It is also interesting to note the relative abundance of edge growth development across the entire district. This can perhaps be attributed to the inclusion of all development types, like roads, within the Built-up classification; thus, suggesting an influence proximity to infrastructure may have on driving more diffuse growth in the BM district. The largest proportion of infill growth, on the other hand, has now been recorded to be in relatively higher proportions towards the periphery of the district at the 22 to 24 kilometre distance boundary. Investigation into this shows urban infilling around land in the old port-town of Muara at the north-easternmost tip of the BM district. The relatively high proportion of infill here can, therefore, be attributed to the inherent shortage in developable land, given its adjacency to protected conservation frontages and the South China Sea.

In contrast to low-levels of compact development in 1991-2001, the following period indicates an increase in AWMEI values, with an average of 0.63 across the BM district. The global increase in the AWMEI from the 1991-2001 time period suggests that overall development in the district is has moved into a phase of densification, characterised by the decrease in edge growth and new growth proportions, and a marked increase in the infill growth development typologies throughout. Edge growth developments are however noted to be particularly high from the 14-kilometre threshold, extending towards the north and northeastern peripheries of the district. Higher levels of new growth are seen in only two areas during this period: the new Katimahar and Mentiri Housing Estates starting at the 20-kilometre boundary from BSB. Infill growth in the district remains high between the 2 to 14 kilometre from BSB, throughout the, now, well-established areas of Berakas, Gadong, and Kianggeh. These developments coincide with the designated footprint of the BM districts urban containment proposed in the NLUMP in 2006.

\subsection{Residential Growth in the Brunei-Muara District}

Residential land-uses in the BM district have been obtained for all study years through the integration of cadastral vectors provided by the Brunei Ministry of Development. Figure 11 illustrates the relative distribution of these residential land-uses in 1981 and 2011. The total area of residential land-cover totalled approximately $23.4 \mathrm{~km}^{2}$ in 1981 , which accounted for approximately 31.8 per cent of the total built-up class. This proportion was increased, close to 36.7 per cent in 2011 or 62.1 $\mathrm{km}^{2}$. It is important to note that provisions for strata titles in Brunei were introduced only in 2009; however, up to 2012, no strata titles had yet been approved (Oxford Business Group, 2015). As such, the overwhelming majority of Brunei's residential land-parcels up to this time still consisted of single-family residences. Higher density dwellings types like flats are typically government-owned and are not included in this study.

Between 1981 and 1991, growth in the BM district was characterised by edge growth extending from BSB to the Northeast of the district. Infill growth is predominantly seen dominant within a 4-kilometre radius of BSB, suggesting a low level of densification within the city centre during this time. However, the opposite is true towards the Southwest of BM, where a more significant number of disconnected residential pockets have been recorded. These new growth development pockets are also seen throughout the 1991-2001 period, with increasing edge growth of the BSB also evident. The correlation coefficient $r$ for 1991-2001 shows a positive correlation between the new growth and distance, where new residential developments are increasing away from the city centre towards the peripheries $(r=0.615)$. The correlation is statistically significant with a $p$ - value of 0.033 with 95 per cent confidence interval.

This diffuse form of development does, however, appear to have declined over the 2001-2011 period. Higher proportions of 


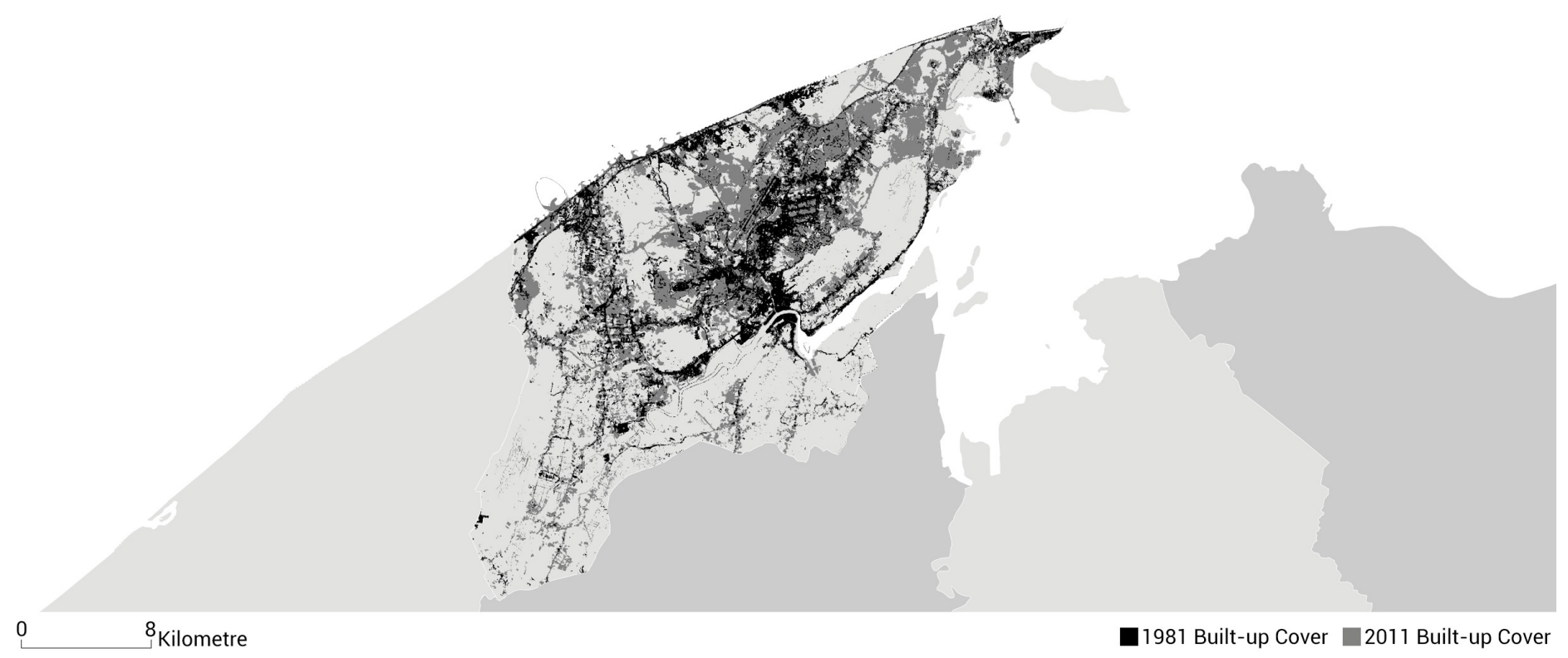

Figure 11: Change in residential land-cover in the Brunei-Muara District between in 1981 and 2011.

residential infill are seen throughout the district, extending towards the northeastern peripheries of the district. Similarly, statistical testing indicates a significant negative correlation $(r=-0.629, p-$ value $=0.028)$ between distance and infill residential development, which affirms infill development happening near the city centre corresponding the Bruneian Government's effort to promote increased densification.

With respect to development compactness, the study has found that global AWMEI values have not significantly differed for 30 years between 1981 and 2001. The mean global AWMEI values for 1981-1991 and 1991-2001 are recorded at 0.29 and 0.25 respectively. However, between the study period of 2001 and 2011, AWMEI values have shown an increase to 0.46. The results of the study suggest that pockets of disconnected residential developments have been features of Brunei's urban landscape prior to both the NBDMP and NLUMP. The relative change in AWMEI values over the entire study period are indicative of early phases of diffuse developments throughout the BM district, with the past decade only seeing marginal increases of compact development.

The growth pattern observed here certainly differs from what was thought to be a more concentric form, as previously noted with the total built-up areas. It further suggests that residential growth in Brunei has previously followed a more diffuse and disconnected pattern, with adjunct and detached new growth neighbourhoods establishing themselves as central loci for subsequent edge and infill growth.

This spatiotemporal pattern is evident in Figure 12 in which the relative proportions of residential growth typologies across various directions from BSB is illustrated. An overwhelming dominance of new growth areas is recorded at the Southwestern peripheries of the BM district between 1981 and 2001. After which, edge growth dominates, following a transition into infill growth, with decreasing distance from the BSB centre. Similar trends are also evident up to 10-kilometre distance threshold Northwest of BSB, where a higher proportion of new growth clusters have perforated these areas and would later transition into edge expansion and infill in subsequent years. This is a growth pattern that has been documented in cities across the world (Herold et al., 2003, Dietzel et al., 2005a b); and, it does appear inevitable as the amount of developable land decreases forcing new growth into a larger contiguous area. 

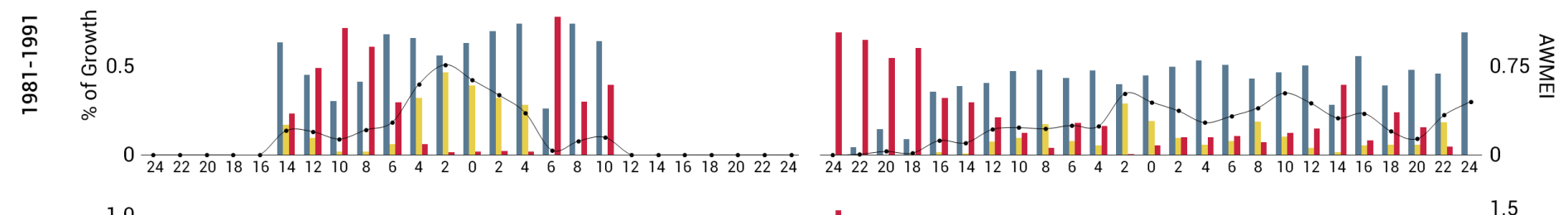
1.0
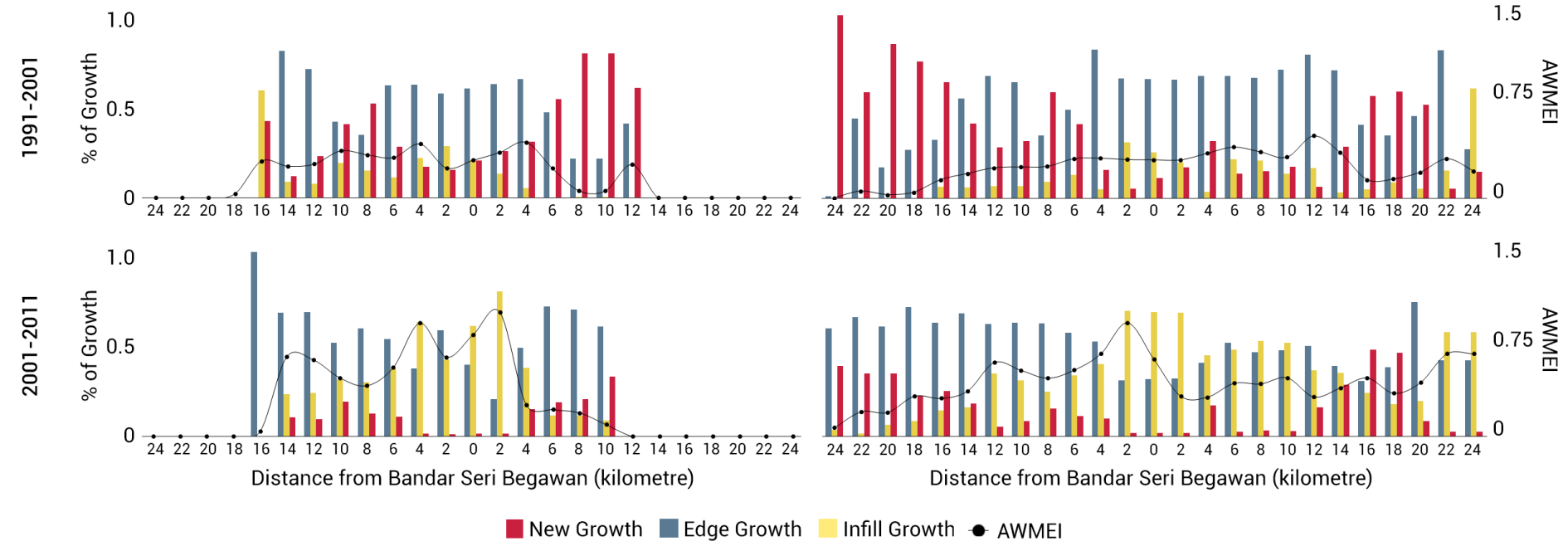

Figure 12: Direction-dependent changes in Area-weighted Mean Expansion Index and proportion of development type moving from Bandar Seri Begawan. 


\section{Discussions}

The results of this study bring into light three main aspects of Brunei's urban growth into consideration. First, it highlights the increasing spread of urbanisation throughout the entire BM district. Second, it considers whether development policy has contributed, or prevented, unnecessary and excessive land-consumption in the country. Lastly, it illustrates the changing development typologies presents over the past 40 years and considers its impacts these may have on Bruneian citizens.

With regard to the BM's rapidly increasing urbanisation, the most apparent cost to available land is seen in the loss of the district's natural landscape. This study's quantification of BM's land-cover has already indicated significant losses to vegetation cover, with increasing degradation of intact rainforests with the rise of disconnected new growth development. The fragmentation of unprotected primary rainforests and mangrove conservation areas are already evident around the Kota Batu, Subok, and Telanai sub-districts; with the remaining intact forests corresponding mainly to conservation rainforest and ridge sites around these sub-districts (DTCP, 2008). It is not within this study's scope to discuss the increasing threat that urban growth has had on Brunei's natural ecosystems. However, it is undoubtedly an issue that warrants closer inspection and more stringent monitoring - particularly, with respect to preservation of the wider Southeast Asian region's biodiversity. It is the onus of this paper, instead, to discuss the efficacy of Brunei's master-plan strategies has been in addressing these issues, in addition to achieving the goals of its broader national development plans.

This study has shown that urban growth, overall, does indeed have links to national development policies, despite Brunei's master-plans being legally unenforceable. Increased new growth and edge growth evident throughout the district in 1991-2001 coincided with the polycentric growth strategy espoused by the NDBMP (1986-2005). Whereas, between 2001-2011, the NLUMP's (2006-2025) advocacy for increased densification within the BM district's urban footprint can also perhaps be denoted by the increased infill growth and AWMEI values calculated throughout the entire stretch of the BM district. With respect to this, full appreciation for the influence development policy has on future land-use is needed to account for their impacts on BM's built form.
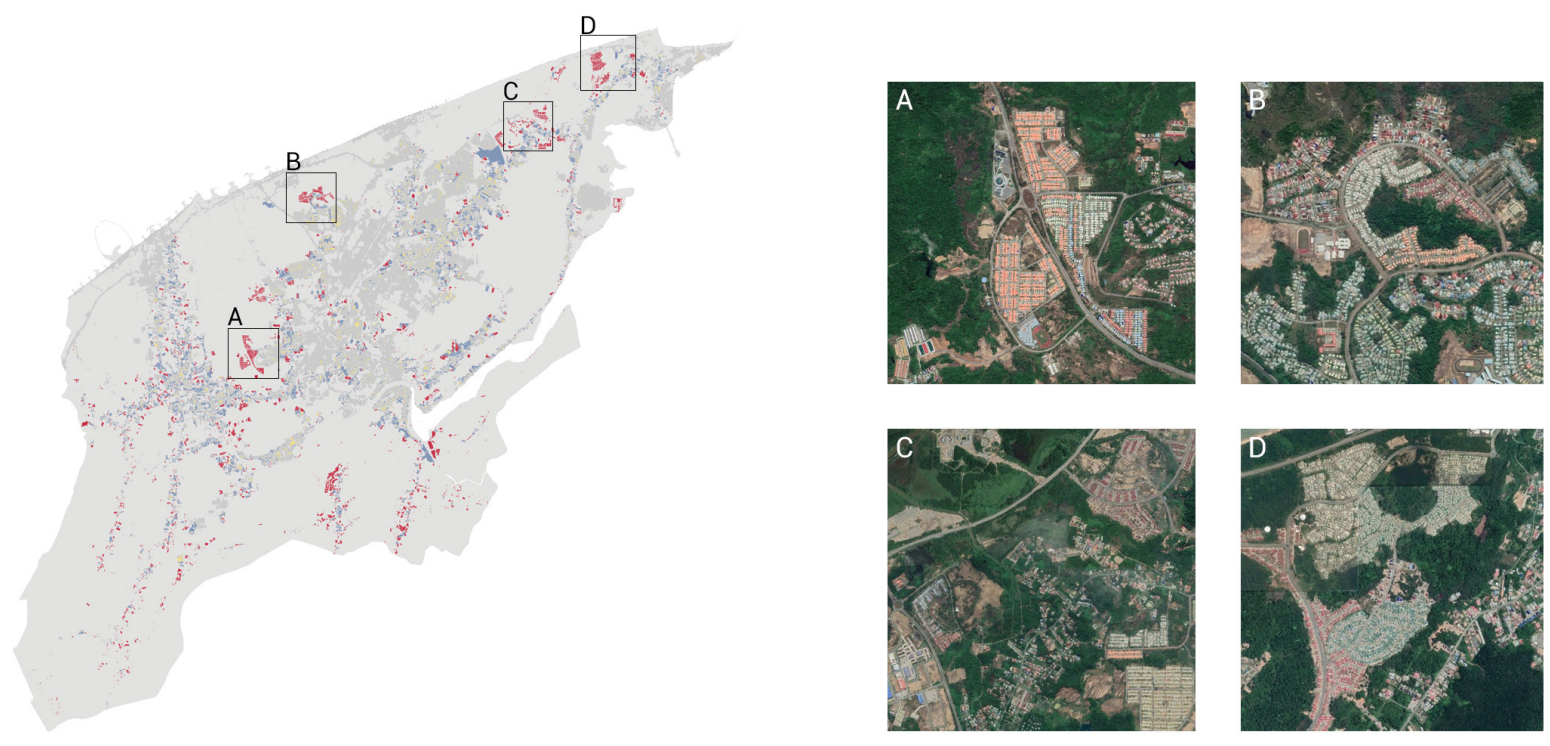

0

${ }^{8}$ Kilometre

New Growth

Edge Growth

Infill Growth

Figure 13: Growth types and areas of interest in the BM district for study year 1981-1991. Inset A: Rimba STKRJ Estate; Inset B: Rimba RPN Estate; Inset C: Lambak Kanan RPN Estate; Inset D: Mentiri RPN Estate.

This is particularly true for the development of residential land-use, which has already been shown to be one of the most prevalent drivers of urban growth in the country. Diffuse and disconnected new growth, indicated by low AWMEI values, has long been present in BM; even prior to the introduction of the NBDMP's polycentric growth strategies in 1986. Considering this, the NBDMP's development policies for polycentric growth appear only as a tool to establish this form of development throughout the BM district. As a result, the government's advocacy for this development form, in addition to the Bruneian population's predilection for the development detached, single-family dwellings (Hamzah and Urayama, 2018), were both instrumental in creating its homogeneous housing estates. New growth development typologies in residential land-use furthermore look to predominantly be RPN and STKRJ estates (ref. Figure 13). This is certainly common throughout the entire BM district, with RPN and STKRJ housing estates accounting for close 80 per cent of the housing stock in some village 
areas (JPKE, 2011).

The implications of this continued low-density, homogeneous urban form on a city's socioeconomic and environmental dimensions nevertheless warrant significant discussion. One of its most tangible effects seen is that of increasing separation between different functional areas of the city, reflected in rising trip-distances. Frumkin et al. (2004) and Zhao (2010) both rightfully maintain that the decreased walkability to essential urban amenities, in turn, reinforces the reliance on motorised transportation. Moreover, whilst public transport typically comes in aid to connect populations in this regard, this does not appear evident in Brunei. The poor state and available choices of public transportation are argued to necessitate the use of private vehicles (Duraman and Hashim, 1998). This is evidenced most clearly in the country's globally high car ownership per capita (CEIC Data, 2017).

The issue of automobile hegemony in Brunei famously reflect the ideas of early critics of Howard (1965)'s Garden City Model, upon which McGarrigle (1994) has asserted to be principle plan on which Brunei's RPN and STKRJ schemes are based on. As Jacobs (1992) has argued, there are likely cascading and detrimental effects these schemes will have on a city's financial, environmental, and social resources. Camagni et al. (2002) highlight that the pervading low-density estates increase the pressure for government to develop adjunct urban services given their increased physical isolation. This has indeed been recognised by the Bruneian Government, with development strategies in the NLUMP requiring the development of smaller ancillary health, education, and religious facilities within housing estates.

This touches on the issue of accessibility in Brunei. Within the strict definition of accessibility by Duranton and Guerra (2016), unfettered expansions of singular land-use types have been shown countless times to be negatively correlated to accessibility to essential urban amenities, quantified both by time- and distance- travelled (Black and Henderson, 1999, Levinson, 1998; Ewing, 2008). Research into this aspect of Brunei's land-use is scarce; however, it remains essential, especially, for government in promoting spatial equity for the Bruneian population. In particular, it is a relevant consideration with respect to formulating policies that should come in aid of increasing the mobility of more vulnerable sects of its population, in light of the country's already limited transportation offerings.

The resulting need to develop ancillary facilities to meet the needs of the Bruneian population not only inflates costs for urban services and required infrastructure development, but as Pedersen and Adler (1999) argues, it also has suffused impacts on the entire urban system - in particular, increasing a city's urban decay. This, again, has been noted empirically by the DTCP (2008) as a contributing factor to the required change in the NLUMP. However, it should be emphasised that the impacts of Brunei's choice for singularly residential, low-density estates have more widespread impacts than just BSB's urban decay. It also has far-reaching impacts on, more importantly, the livelihood and lived-experience of Bruneian residents. With the country's already established approach to public housing following strict cultural and socioeconomic criteria, the added issue of isolated low-density housing exacerbates possible segregation by low-income and geography.

As demonstrated by Fulton et al. (2001) and Powell (1999), the creation of ethnic and income-based enclaves are damaging to citizens' perceived experience of the built environment. It contributes to decreasing social-stability in both a physical and social capacity. This has been argued by Jacobs and Appleyard (1987), Nasar and Julian (1995), and Bramley and Power (2009) to exacerbate tensions within different demographic and socioeconomic groups. Moreover, as a result, the fragmentation of the urban system becomes something deeply entrenched within its residents, themselves.

Considering the many detrimental implications of Brunei's current urban form now discussed, it is reasonable to reiterate the study's primary objective of how planning has influenced its growth thus far. In many ways, it speaks of how the current situation of development in Brunei has more broadly become a product of heavy-handed policies that prohibit urban diversity, social mobility, integration, and interaction - and, with that, how development without forethought can be disproportionately deleterious to demographic groups within the nation.

\section{Conclusions}

This paper has now presented a 40-year observation of the spatiotemporal changes in land-use and land-cover in Brunei Darussalam's capital district, BM. It has further categorised its urban form into distinct typologies, with broader consideration to their relationship with the country's overarching national development policies. Urban growth here, as with many other cities, is a continuously unfolding and complicated process. However, the influence of development policy and the impacts projects undertaken by government within this scope cannot be overemphasised. As such, care needs to be taken concerning the fit of development policy within Brunei; and, certainly within the wider Southeast Asia region. The synoptic nature of the conducted research, as well as the possibility of classification errors inherent to remote-sensing analyses, reiterates this need for caution in the generalisation of Brunei's land-use and land-cover changes. Nevertheless, the observed trends 
raise once more a need for closer inspection and monitoring of the country's current development trajectory. The larger argument of policy and urban growth in Brunei resurfaces the extensive debate that top-down planning may not necessarily function in favour of urban residents. In a country as young as Brunei, and, likewise, in the many other fast-developing cities in Southeast Asia, understanding the ramifications of such clenched-fist implementation of development policies on demographics, land-consumption, and land-use is undeniably important. It is acknowledged that, whilst a more formal system of land-use and land-zoning is considered underdeveloped in the country, the current state of development may perhaps raise calls for a more holistic view of how land is currently being used. In particular, this brings into question the congruity of large-scale, single-use projects with respect to the country's wider urban system and natural environment. In Brunei, there are nevertheless still promising trends evident in land-use that suggests a potential for more conscientious development regulation if policies, particularly with regard to its many national housing projects, are also thoughtfully considered. This is certainly a pressing issue; and, with only 5 per cent of land left available for development, discourse about Brunei's urban growth is more urgent than ever.

\section{Conflict of interest}

The authors declare that they have no conflict of interest.

\section{References}

Aban, J. E., Duane, W., and Yit, G. V. Y. (2011). The potential impact of urbanisation on climate change: Brunei Darussalam case study. 44th EAROPH 83 IFHP Regional Planning Conference 2011, pages 1-13.

Anderson, J. R., Hardy, E. E., Roach, J. T., and Witmer, R. E. (1976). A land use and land cover classification system for use with remote sensor data. U.S. Geological Survey Circular, 671:1:36.

Bakar, N. S. H. A. (2008). The impact of British administration over Brunei's society, 1906-1984. The Second Joint Seminar of FASS UBD and IOC UT: Asian Societies and Cultures in the Eyes of Bruneian and Japanese Researchers, pages 1-11.

Becek, K. (2010). Brunei Darussalam's way to the future through modern mapping. Southeast Asia: A Multidisciplinary Journal, 10:1-9.

Bengston, D. N., Fletcher, J. O., and Nelson, K. C. (2004). Public policies for managing urban growth and protecting open space: policy instruments and lessons learned in the united states. Landscape and urban planning, 69(2-3):271-286.

Bettencourt, L. and West, G. (2010). A unified theory of urban living. Nature, 467(7318):912-913.

Bhatti, S. S. and Tripathi, N. K. (2014). Built-up area extraction using Landsat 8 OLI imagery. GIScience 83 Remote Sensing, 51(4):445-467.

Black, D. and Henderson, V. (1999). A theory of urban growth. Journal of political economy, 107(2):252-284.

Boori, M. S., Choudhary, K., Kupriyanov, A., and Kovelskiy, V. (2016). Satellite data for Singapore, Manila and Kuala Lumpur city growth analysis. Data in brief, 7:1576-1583.

Bramley, G. and Power, S. (2009). Urban form and social sustainability: the role of density and housing type. Environment and Planning B: Planning and Design, 36(1):30-48.

Camagni, R., Gibelli, M. C., and Rigamonti, P. (2002). Urban mobility and urban form: the social and environmental costs of different patterns of urban expansion. Ecological economics, 40(2):199-216.

Caro, R. A. (1974). The power broker: Robert Moses and the fall of New York. Alfred A Knopf Incorporated.

CEIC Data (2017). Brunei motor vehicle registered 2005-2015. [Online; posted 27-June-2017].

Chen, W., Liu, L., and Zhang, C., Wang, J., Wang, J., and Pan, Y. (2004). Monitoring the seasonal bare soil areas in Beijing using multitemporal TM images. IGARSS 2004. 2004 IEEE International Geoscience and Remote Sensing Symposium, 5:3379-3382.

Chandler, T. (1987). Four thousand years of urban growth: an historical census. Lewiston New York St. David's University Press 1987.

Dietzel, C., Herold, M., Hemphill, J. J., and Clarke, K. C. (2005a). Spatio-temporal dynamics in California's central valley: Empirical links to urban theory. International Journal of Geographical Information Science, 19(2):175-195.

Dietzel, C., Oguz, H., Hemphill, J. J., Clarke, K. C., and Gazulis, N. (2005b). Diffusion and coalescence of the Houston metropolitan area: evidence supporting a new urban theory. Environment and Planning B: Planning and Design, $32(2): 231-246$.

DTCP (2008). National Land Use Master Plan 2006-2025. Number 1 of 1. Brunei Darussalam, Ministry of Development, Department of Town and Country Planning. 
DTCP (2015). Brunei Muara District Plan. Number 1 of 1. Brunei Darussalam, Ministry of Development, Department of Town and Country Planning.

Duraman, I. and Hashim, A. A. H. (1998). Brunei Darussalam: developing within its own paradigm. Southeast Asian Affairs, 25:53.

Duranton, G. and Guerra, E. (2016). Urban accessibility: Balancing land use and transportation.

Estoque, R. C. and Murayama, Y. (2015). Intensity and spatial pattern of urban land changes in the megacities of Southeast Asia. Land Use Policy, 48:213-222.

Ewing, R. H. (2008). Characteristics, causes, and effects of sprawl: A literature review. In Urban ecology, pages 519-535. Springer.

Florida, R. (2002). The economic geography of talent. Annals of the Association of American geographers, 92(4):743-755.

Foody, G. M. (2002). Status of land cover classification accuracy assessment. Remote sensing of environment, 80(1):185-201.

Frumkin, H., Frank, L., and Jackson, R. J. (2004). Urban sprawl and public health: Designing, planning, and building for healthy communities. Island Press.

Fulton, W. B., Pendall, R., Nguyen, M., and Harrison, A. (2001). Who sprawls most?: How growth patterns differ across the US. Brookings Institution, Center on Urban and Metropolitan Policy Washington, DC.

Glaeser, E. L. and Kahn, M. E. (2004). Sprawl and urban growth. In Handbook of regional and urban economics, volume 4, pages 2481-2527. Elsevier.

Hamdi, M. F. Z., Abdullah, N., and Narudin, H. D. (2017). Space, place, and identity: How migration have transformed Kampong Ayer (Brunei). Institute of Asian Studies, 1(28):1-22.

Hamzah, H. H. B. H. (2017). A Study on Promoting Land Readjustment in Support of Compact Strategy for Efficient Urban Development in South East Asia: Case Study of Brunei. PhD thesis, Mie University.

Hamzah, H. H. B. H. and Urayama, M. (2018). Land use pattern of private housing development since the introduction of Brunei's compact strategy. J. Archit. Plann., 82(733):705-714.

Harvey, D. (2008). The right to the city. International journal of urban and regional research, 27(4), 939-941.

Hashim, A. A. H. (2010). Challenges in achieving wawasan 2035 goals: Economic diversification in perspective. CSPS Strategy and Policy Journal, 1(1):29-54.

Haug, S., Michaels, A., Biber, P., and Ostermann, J. (2014). Plant classification system for crop/weed discrimination without segmentation IEEE Winter Conference on Applications of Computer Vision, 1142-1149.

Henderson, J. V. (2003). Marshall's scale economies. Journal of urban economics, 53(1):1-28.

Herold, M., Goldstein, N. C., and Clarke, K. C. (2003). The spatiotemporal form of urban growth: measurement, analysis and modelling. Remote sensing of Environment, 86(3):286-302.

Horton, A. (1986). British administration in Brunei 1906-1959. Modern Asian Studies, 20(2):353-374.

Howard, E. (1965). Garden cities of to-morrow, volume 23. Mit Press.

Jacobs, A. and Appleyard, D. (1987). Toward an urban design manifesto. Journal of the American Planning Association, $53(1): 112-120$.

Jacobs, J. (1992). The Death and Life of Great American Cities. Vintage Books ed. Vintage Books.

Jones, D. S. (2010). Land registration and administrative reform in Southeast Asian states: Progress and Constraints. International Public Management Review, 11(1):67-89.

Jones, G. W. (1997). The throughgoing urbanisation of East and Southeast Asia. Asia Pacific Viewpoint, 38(3):237-249.

JPKE (2011). Brunei Darussalam census 2011. Prime Minister's Office Department of Statistic.

JPKE (2017). Report of the mid-year statistics estimates. [Online; accessed 10-November-2018].

Levinson, D. M. (1998). Accessibility and the journey to work. Journal of Transport Geography, 6(1):11-21.

Lillesand, T., Kiefer, R. W., and Chipman, J. (2014). Remote sensing and image interpretation. John Wiley \& Sons.

Lim, C.-Y. (2004). Southeast Asia: the long road ahead. World Scientific.

Liu, X., Li, X., Chen, Y., Tan, Z., Li, S., and Ai, B. (2010). A new landscape index for quantifying urban expansion using multi-temporal remotely sensed data. Landscape ecology, 25(5):671-682.

Madhavan, B. B., Kubo, S., Kurisaki, N., and Sivakumar, T. (2001). Appraising the anatomy and spatial growth of the Bangkok metropolitan area using a vegetation-impervious-soil model through remote sensing. International Journal of Remote Sensing, 22(5):789-806.

Mansurnoor, A. (1997). Water village until the foundation of the land-based settlement: A Malay Muslim community and state in Brunei. In Islamic urbanism in human history: Political power and social networks, pages 171-210. London: Kegan Paul International.

McGarrigle, D. (1994). Unsettling Brunei. Australian Planner, 31(3):159-164.

Montgomery, M. R. (2008). The urban transformation of the developing world. science, 319(5864):761-764.

Moretti, E. (2004). Human capital externalities in cities. In Handbook of regional and urban economics, volume 4, pages 2243-2291. Elsevier. 
Nasar, J. L. and Julian, D. A. (1995). The psychological sense of community in the neighborhood. Journal of the American Planning Association, 61(2):178-184.

Nong, D. H., Lepczyk, C. A., Miura, T., and Fox, J. M. (2018). Quantifying urban growth patterns in Hanoi using landscape expansion modes and time series spatial metrics. PloS one, 13(5):e0196940.

Oxford Business Group (2011). The Report: Brunei Darussalam 2011.

Oxford Business Group (2015). Poised for growth: Diversification plans will present new opportunities.

Oxford Business Group (2016). Development plans for Brunei Darussalam's Bandar Seri Begawan to create new opportunities.

Pedersen, D., S. V. and Adler, J. (1999). Sprawling, sprawling. Newsweek, pages 23-27.

Powell, J. (1999). Race, poverty, and urban sprawl: Access to opportunities through regional strategies. In Forum for Social Economics, volume 28, pages 1-20. Taylor \& Francis.

Rimmer, P. J. and Dick, H. W. (2009). The city in Southeast Asia: Patterns, processes and policy. NUS Press.

Roberts, C. (2011). Brunei Darussalam: Consolidating the foundations of its future? Southeast Asian Affairs, 2011(1):33-50.

Rouse Jr, J. W., Haas, R. H., Schell, J., and Deering, D. (1973). Monitoring the vernal advancement and retrogradation (green wave effect) of natural vegetation. NASA Technical Reports Server.

Seto, K. C., Sánchez-Rodríguez, R., and Fragkias, M. (2010). The new geography of contemporary urbanization and the environment. Annual review of environment and resources, 35:167-194.

Sharifi, A., Chiba, Y., Okamoto, K., Yokoyama, S., and Murayama, A. (2014). Can master planning control and regulate urban growth in Vientiane, Laos? Landscape and Urban Planning, 131:1-13.

Sheng, Y. K. and Thuzar, M. (2012). Urbanization in Southeast Asia: issues 63 impacts. Institute of Southeast Asian Studies.

Sinclair, S. (2017). Urbanisation and labour markets in developing countries. Routledge.

Thomson, C. N. and Hardin, P. (2000). Remote sensing/GIS integration to identify potential low-income housing sites. Cities, 17(2):97-109.

USGS (2019). Landsat missions.

World Resource Institute (2011). Country Boundaries of Southeast Asia.

$\mathrm{Xu}, \mathrm{H}$. (2006). Modification of normalised difference water index (NDWI) to enhance open water features in remotely sensed imagery. International journal of remote sensing, 27(14):3025-3033.

Yunos, R. (2008). A Bruneian's castle: National housing. the history of public housing programs in Brunei. The Brunei Times.

Zain, A. F., Permatasari, P. A., Ainy, C. N., Destriana, N., Mulyati, D. F., and Edi, S. (2015). The detection of urban open space at Jakarta, Bogor, Depok, and Yangerang-Indonesia by using remote sensing technique for urban ecology analysis. Procedia Environmental Sciences, 24:87-94.

Zhao, P. (2010). Sustainable urban expansion and transportation in a growing megacity: Consequences of urban sprawl for mobility on the urban fringe of Beijing. Habitat International, 34(2):236-243. 